\title{
Política cultural pública en México y su eficacia
}

\author{
Rubén Cervantes Hernández \\ Universidad Autónoma de Chihuahua, México \\ rubencervantesh1@gmail.com \\ https://orcid.org/0000-0002-9390-9461
}

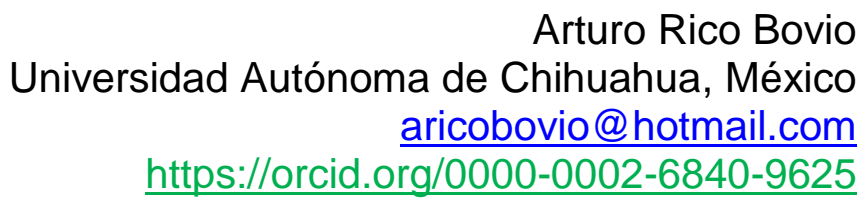

Recibido: 27 de marzo de 2018

Aceptado: 30 de abril de 2018

\section{Resumen}

Este ensayo tiene como objeto problematizar los procesos de la política cultural que marcan los espacios socio-culturales-administrativos ofertados por el gobierno mexicano. Elabora una caracterización general de las dinámicas del desarrollo humano y las políticas culturales de forma transversal. Describe la relación de las políticas culturales con los tratados internacionales y muestra el contexto nacional de México. Ofrece una visión histórica general de las políticas culturales, los antecedentes de estudios del consumo cultural y el PIB cultural de México. Aborda la interconexión de la Secretaría de Cultura con otras Secretarías.

Esta investigación pone las bases para identificar y evaluar el desarrollo humano y otras problemáticas de las políticas culturales en el contexto específico de México.

\section{(C) $(\Theta \odot$}

La Revista Estudios es editada por la Universidad de Costa Rica y se distribuye bajo una Licencia Creative Commons Atribución-NoComercial-CompartirIgual 3.0 Costa Rica. Para más información envíe un mensaje a 
Palabras clave: Políticas Culturales; Cultura; Identidad; México; Interconexiones culturales.

\title{
Mexican's public cultural policies and its effectiveness
}

\begin{abstract}
The purpose of this essay is to problematize the processes of cultural policy that mark the socio-cultural-administrative spaces offered by the Mexican government. Produce a general characterization of the dynamics of human development and cultural policies in a transversal way. Describes the relationship of cultural policies with international treaties and shows the national context of Mexico. It offers a general historical view of cultural policies, the background of studies of cultural consumption and the cultural GDP of Mexico. It addresses the interconnection of the Ministry of Culture with other Secretariats.

This research provides the basis for identifying and evaluating human development and other issues related to cultural policies in the specific context of Mexico.
\end{abstract}

Keywords: Cultural Policies; Culture; Identity; Mexico; Cultural interconnections.

\section{Introducción}

El ser humano creó al Estado para ser feliz, tener seguridad, bienestar en todos los ámbitos. El Estado debe garantizar la satisfacción de estas necesidades y a la vez tiene que velar por su propia estabilidad; para lograrlo genera las políticas públicas que se ejercen por medio de instituciones sociales, económicas, políticas, culturales, entre otras. Véase la figura 1 que presenta de manera filosófica la búsqueda del ser humano por ser feliz y obtener beneficios diversos; esto explica la creación del Estado, cuya razón de ser es buscar el bienestar de la población a través de poner las bases y favorecer el desarrollo humano. El lograr sus objetivos le permite a la vez velar por su propia preservación y/o permanencia del ciclo, que regresa a ocuparse nuevamente de las necesidades y satisfactores de los individuos y sus búsquedas, que demandan la creación de nuevas políticas culturales.

\section{(c) (i) (2)}

La Revista Estudios es editada por la Universidad de Costa Rica y se distribuye bajo una Licencia Creative Commons Atribución-NoComercial-CompartirIgual 3.0 Costa Rica. Para más información envíe un mensaje a 


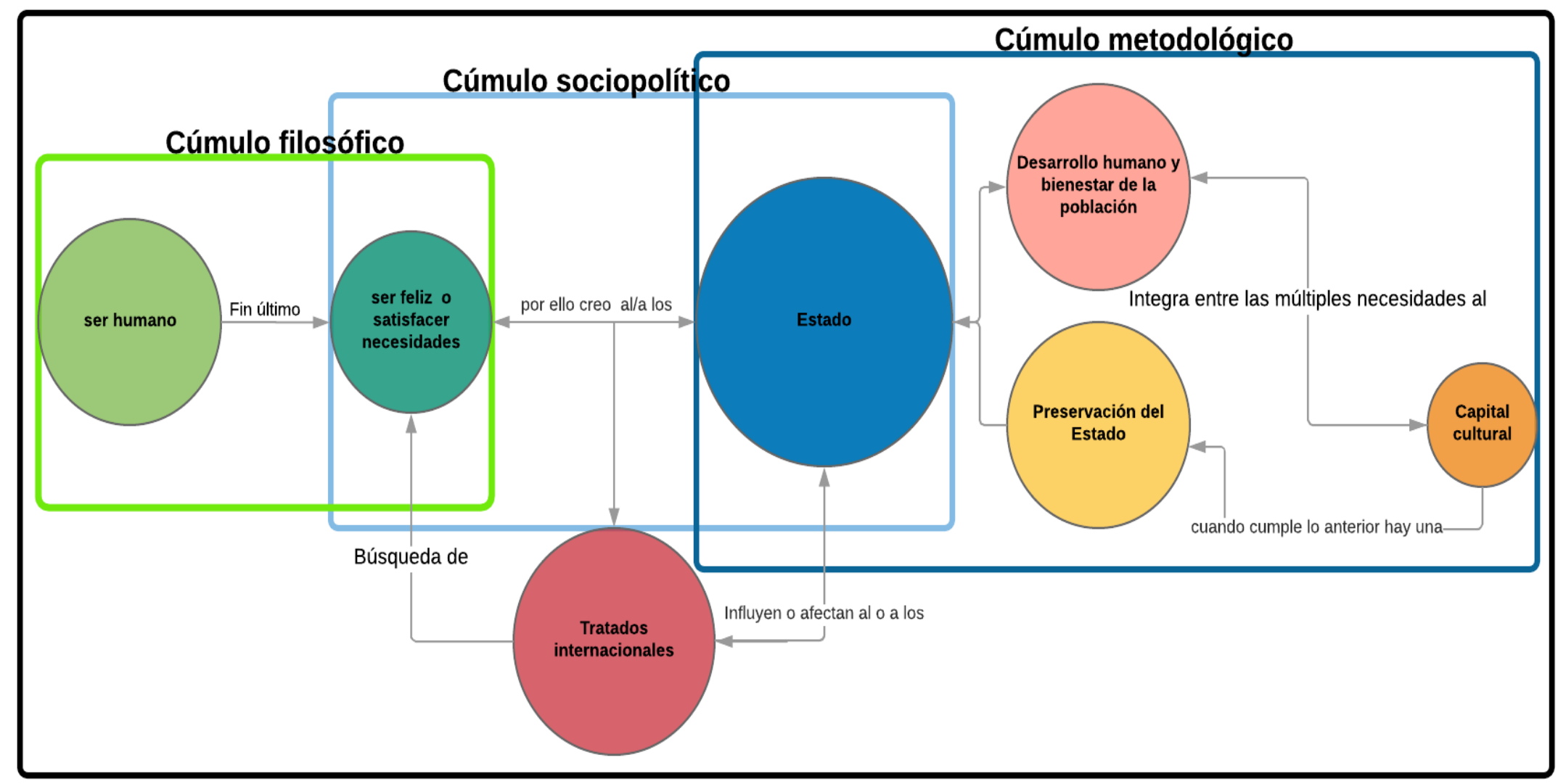

Figura 1.- Modelo de la dinámica de los fines del ser humano y su vinculación con el Estado y los tratados internacionales. Fue construido en base a la figura de Trejo Hermida, O. (2017). Valores de Bienestar y Nacionalismo en Civiles y Militares. Una aproximación a la seguridad nacional en México. Tesis Doctoral. Centro de Estudios Superiores Navales. México.

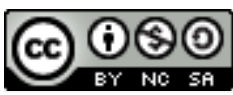

La Revista Estudios es editada por la Universidad de Costa Rica y se distribuye bajo una Licencia Creative Commons Atribución-NoComercialCompartirIgual 3.0 Costa Rica. Para más información envíe un mensaje a revistaestudios.eeg@ ucr.ac.cr. 
Para lograr el cometido del Estado consignado en la figura 1, que tiene como meta natural el desarrollo humano, en cuyas múltiples facetas se incluye a la Cultura, se establecen las políticas públicas, que en países como México se ejercen por diversas Secretarías; cada una implementa programas que se combinan para lograr los objetivos determinados por los gobernantes en turno, en base a los tratados internacionales. Dichos objetivos no se podrían alcanzar sin el concurso de esa interdisciplinariedad institucional.

Para efectos del presente ensayo el desarrollo humano se entiende como:

...un proceso en el cual se amplían las oportunidades (...) las tres más esenciales son disfrutar de una vida prolongada y saludable, adquirir conocimientos y tener acceso a los recursos para lograr un nivel de vida decente, si no se poseen estas oportunidades esenciales, muchas otras alternativas continuaran siendo inaccesibles

Pero el desarrollo humano no termina allí. Otras oportunidades, altamente valoradas por muchas personas que van desde la libertad política, económica y social, hasta la posibilidad de ser creativo y productivo, respetarse a sí mismo y disfrutar de la garantía de derechos humanos.

El desarrollo humano tiene dos aspectos. La formación de capacidades humanas -tales como un mejor estado de salud, conocimientos y destrezasy el uso que la gente hace de las capacidades adquiridas -para el descanso, producción o las actividades culturales, sociales y políticas. Si el desarrollo humano no consigue equilibrar estos dos aspectos puede generarse una considerable frustración humana (PNUD, 1990, p. 34).

\section{(C) $(00$}

La Revista Estudios es editada por la Universidad de Costa Rica y se distribuye bajo una Licencia Creative Commons Atribución-NoComercial-CompartirIgual 3.0 Costa Rica. Para más información envíe un mensaje a 


\section{Necesidades humanas y Cultura}

Rico Bovio Arturo

Para comprender el concepto del desarrollo humano y el bienestar de la población, que pide ampliar las oportunidades de acceso a la Cultura para todos los ciudadanos, se da revisión a la pirámide de las necesidades de Maslow, el modelo de los siete niveles de conciencia de Barrett y la teoría de las valencias corporales de Rico Bovio, resumidas en las figuras 2, 3 y 4, para comprender a través de ellas los requerimientos que se deben alcanzar para lograr el cometido de la oferta y el consumo cultural. Es evidente que si se encuentra a una población que carece de los satisfactores de sus necesidades más urgentes, la oferta de la política cultural pública será reducida, por obra de las prioridades que establece el ejercicio del gobierno. Situación que se agrava con las mermas presupuestales que se producen dentro del aparato gubernamental, por vicios o corruptelas que tienen un impacto negativo en la población.

\section{(c) (i) (2)}

La Revista Estudios es editada por la Universidad de Costa Rica y se distribuye bajo una Licencia Creative Commons Atribución-NoComercial-CompartirIgual 3.0 Costa Rica. Para más información envíe un mensaje a 


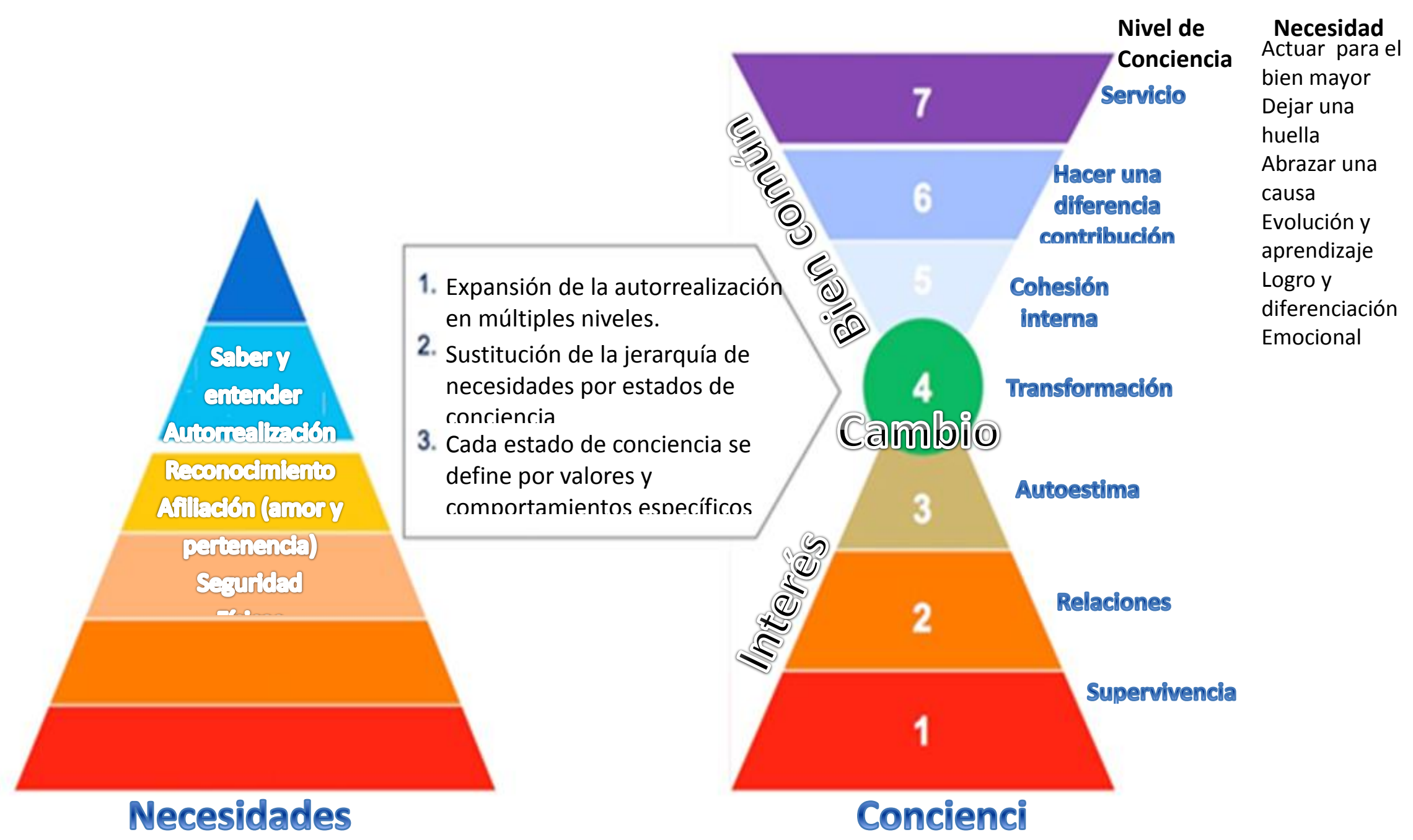

Figura 2.- Progreso del modelo de las necesidades de Maslow a los siete niveles de conciencia de Barrett. Figura propia construida en base a las páginas electrónicas de Maslow, A.H. (1943) y Barrett, R. (2018).

\section{(c) 1 (1)(2)}

La Revista Estudios es editada por la Universidad de Costa Rica y se distribuye bajo una Licencia Creative Commons Atribución-NoComercialCompartirIgual 3.0 Costa Rica. Para más información envíe un mensaje a revistaestudios.eeg@ucr.ac.cr. 


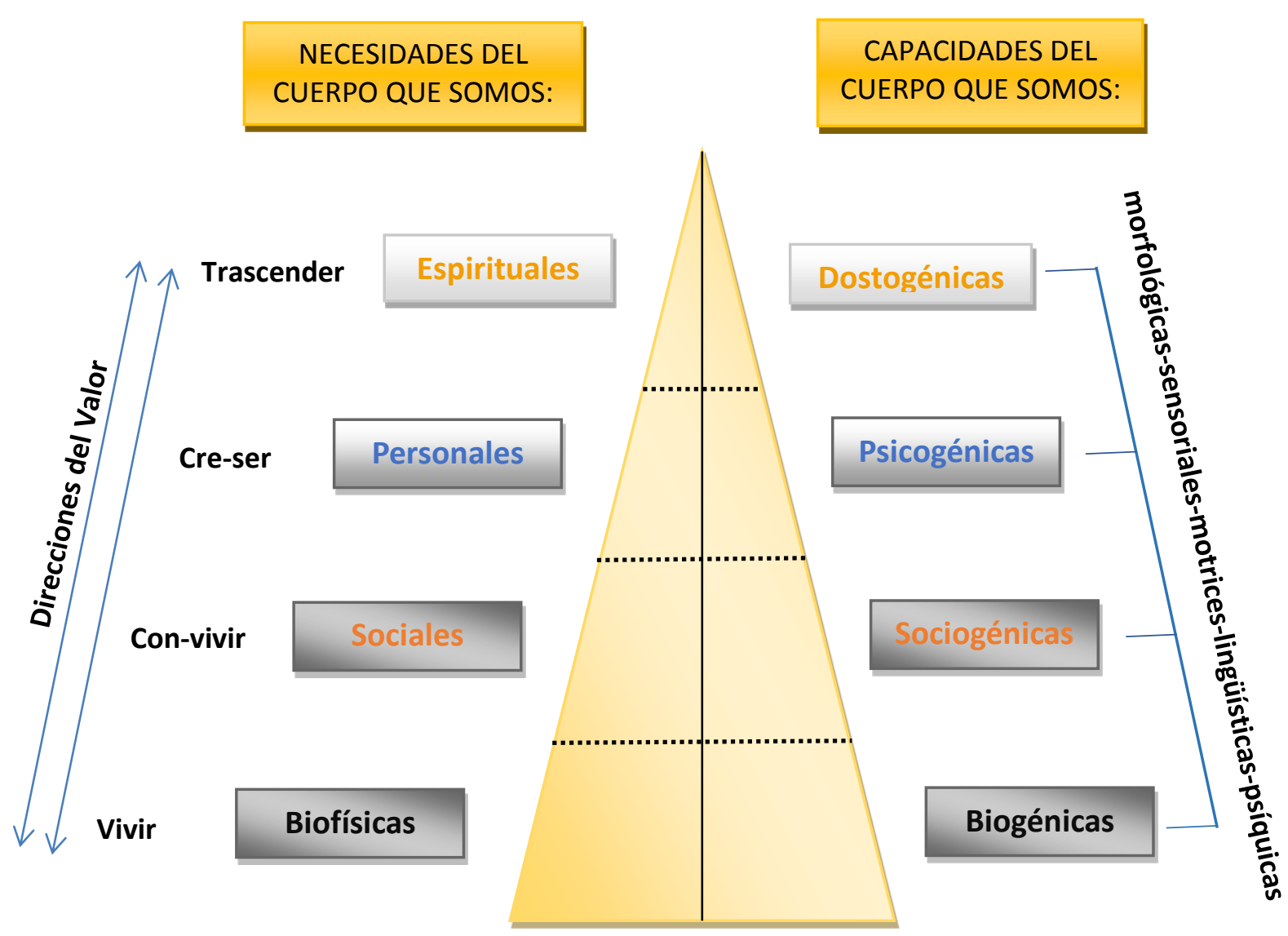

Figura 3.- Correlación entre necesidades y capacidades del cuerpo que somos. Las primeras sirven de fundamento a una Teoría del Valor: Hay un orden fundatorio que va desde la vida hasta la trascendencia, pero también, en orden inverso, la jerarquía de los valores viene de la trascendencia a la vida. Así se entiende el valor del sacrificio voluntario de una vida que se entrega por los demás (Rico Bovio, 1990, 2017).

\section{@ $\odot \Theta \odot$}

La Revista Estudios es editada por la Universidad de Costa Rica y se distribuye bajo una Licencia Creative Commons Atribución-NoComercialCompartirIgual 3.0 Costa Rica. Para más información envíe un mensaje a revistaestudios.eeg@ ucr.ac.cr. 
La pirámide de Maslow consignada en la figura 2, abarca cinco niveles de necesidades que se deben escalar en ese mismo orden:

1. Las biológicas, básicas o físicas, se refieren a lo más indispensable o urgente, como tener salud, comida, descanso, relaciones sexuales, entre otras.

2. Las de seguridad incluyen los aspectos que hacen al ser humano sentirse protegido, como tener dinero (trabajo), seguridad física, propiedad privada (vivienda), entre otras. Un factor relevante de este nivel es el no padecer la incertidumbre de perder las anteriores prerrogativas.

3. Las de afiliación o sociales se relacionan con sentirse integrados en la sociedad y el desarrollo afectivo; tener amigos, familia, pareja, entre otros.

4. Las de reconocimiento y autoestima, abarcan el poder alcanzar el reconocimiento, la confianza, el respeto de los demás o el éxito.

5. Las de autorrealización, localizadas en la cima de la pirámide, se relacionan a las actividades de creatividad, tales como escribir un libro, hacer una obra de arte, entre otras. Constituyen la moralidad y el desarrollo del potencial del ser humano (Maslow, 1943).

Sin embargo hay dos autores que han ampliado la teoría de Maslow, los cuales son Barrett y Rico Bovio, donde Barrett convirtió la primera y segunda necesidad de la pirámide de Maslow en la primera conciencia de su teoría que trata de la supervivencia que busca la salud, la nutrición, las finanzas sanas, la estabilidad, la auto-defensa, que si hay un exceso de atención o falta de atención se puede convertir en violencia, enojo, corrupción, territorialismo, entre otros. En la figura 3 de Rico Bovio en el primer nivel de las necesidades biofísicas es el equivalente a los anteriores. En la teoría de Maslow el tercer nivel se equipara con la segunda conciencia de Barrett donde trata de las relaciones familiares, las amistades, la pertenencia, la comunicación abierta y los rituales que en su exceso o falta de estos se pueden tornar en vergüenza, celos, juicios, conflictos y chismes. Con Rico Bovio es en el segundo escalón de la pirámide que se

\section{(c) (i) (2)}

La Revista Estudios es editada por la Universidad de Costa Rica y se distribuye bajo una Licencia Creative Commons Atribución-NoComercial-CompartirIgual 3.0 Costa Rica. Para más información envíe un mensaje a 
denominó como sociogénicas. El cuarto paso de Maslow se ve reflejado en la tercer conciencia de Barrett, que es el reconocimiento social de cualquier índole. A diferencia de ellos, el tercer escalón de las necesidades de la pirámide de Rico Bovio equivale a la autorrealización de Maslow, que es el paso cinco y final. La cuarta conciencia de Barrett, lugar donde ocurre una transformación de la evolución y del aprendizaje; donde se puede trascender. Es similar al paso cuarto de Rico Bovio que llama de las necesidades espirituales porque se refieren a la trascendencia de la persona hacia los demás, que es un equivalente a las siguientes tres conciencias últimas de Barrett, que son: la quinta encontrar sentido en la existencia (se refleja en la integridad, la autenticidad, la creatividad, la pasión, la honestidad y la confianza). La sexta trata de hacer una diferencia en la comunidad mediante la significación, la colaboración, la empatía, entre otras y finalmente la séptima es el servicio a la humanidad y al planeta, donde se persigue la compasión, humildad y el pensar en las generaciones futuras (Barrett, 2018). Rico Bovio añade en paralelo a las necesidades y las capacidades, que por naturaleza se tienen; son medios para cubrir las necesidades o impulsos que mueven a las personas. En conjunto las necesidades y las capacidades son las "valencias del cuerpo" que socialmente son valoradas de diversas formas, más o menos correspondientes a lo que por naturaleza favorecen (Rico Bovio, 1990, 2017). Sin embargo, para comprender más la teoría de Rico Bovio se anexa un esquema alternativo a la figura 3 , véase la figura 4.

\section{c) (i) (2)}

La Revista Estudios es editada por la Universidad de Costa Rica y se distribuye bajo una Licencia Creative Commons Atribución-NoComercial-CompartirIgual 3.0 Costa Rica. Para más información envíe un mensaje a 


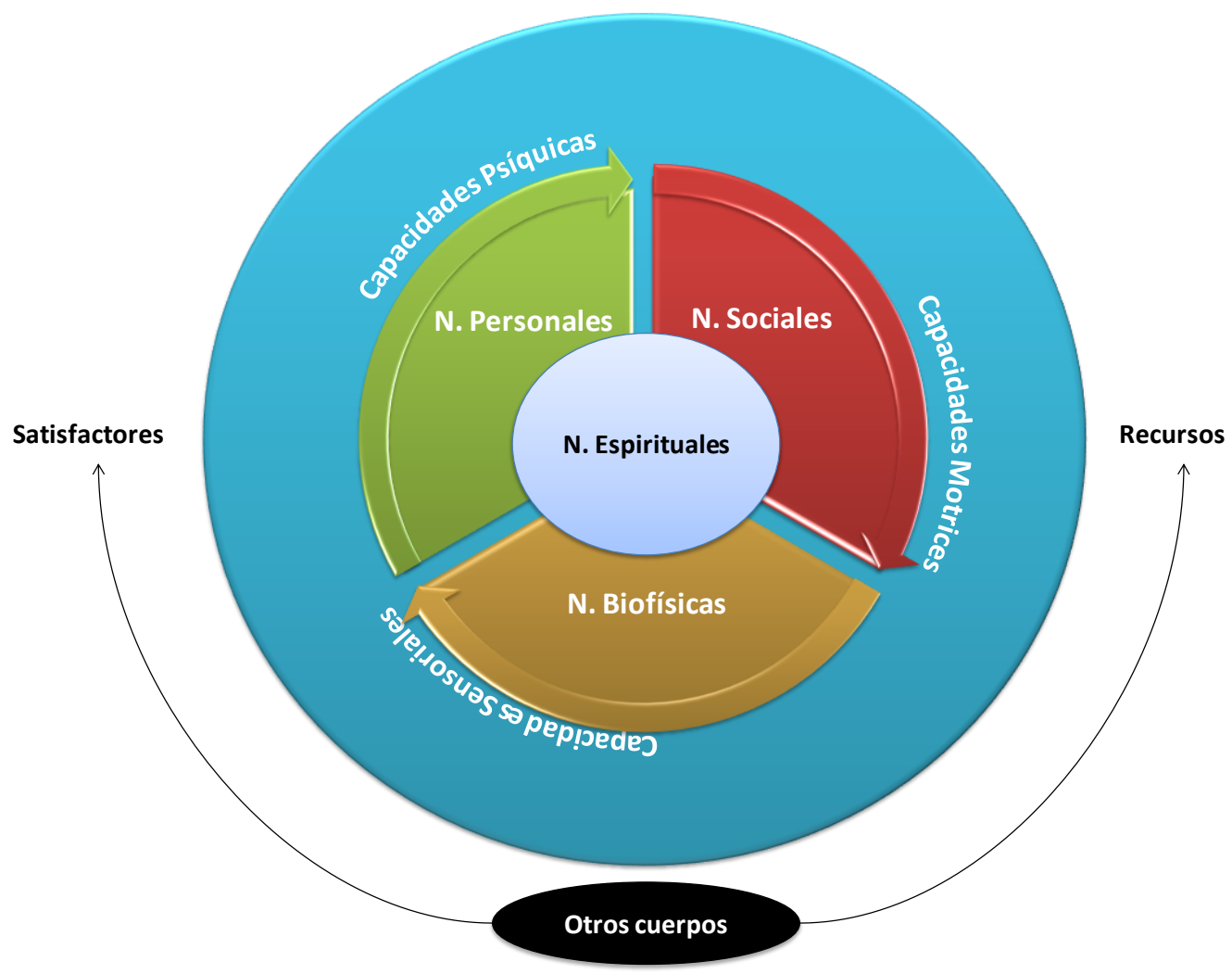

Figura 4.- El cuerpo que somos junto con las valencias corporales, esquema alternativo (Rico Bovio, 1990, 2017).

La tercera teoría en torno a las necesidades humanas aportada por Rico Bovio, se refiere al humano como un conjunto de "valencias corporales" (figuras 3 y 4), que configuran un sistema de necesidades y capacidades que se corresponden unas a otras como impulsos y recursos naturales del cuerpo que somos. De manera similar a Maslow y Barrett, ve al ser humano como un ser en proceso de desarrollo hasta su plenitud, que puede o no alcanzarse, según sean las condiciones sociales en que se encuentra inmerso. Aquí lo biofísico se identifica con la supervivencia y la salud; lo social con el lenguaje, la comunicación, el afecto, la sexualidad y la información; lo personal con el desarrollo de una identidad propia que desemboca en la creatividad que manifiesta la singularidad. Por último lo espiritual expresa el sentido general de donación de lo propio, de aquello que manifiesta nuestra personalidad, una

\section{(C) $\odot \Theta \odot$}

La Revista Estudios es editada por la Universidad de Costa Rica y se distribuye bajo una Licencia Creative Commons Atribución-NoComercial-CompartirIgual 3.0 Costa Rica. Para más información envíe un mensaje a revistaestudios.eeg@ucr.ac.cr. 
especie de "florecimiento" hacia los demás, en la búsqueda, consciente o no, de la trascendencia.

La Cultura, en cualquiera de los tres marcos teóricos, se entendería entonces como un muy importante satisfactor de necesidades personales de realización y trascendencia.

\section{El contexto de México y el desarrollo humano}

En México el índice de percepción de la corrupción 2017, según empresarios y analistas encuestados, donde la calificación de 100 es ausencia de corrupción y de 0 para la percepción de muy corrupta, México se posiciona con el lugar 29 (Transparency International, 2017b), a diferencia del índice de percepción de la corrupción 2016 donde México se encontraba en los 30 puntos (Secretariat Transparency International \& International, 2016), en 2015 y 2014 fue posicionado con 35 puntos, en 2013 y 2012 con 34 puntos. Se observa que a través del presente sexenio se mantuvo del 2012 al 2015 entre 34 y 35, y en los dos últimos años (2016 y 2017) hubo un aumento considerable de la percepción de corrupción (Transparency International, 2017a). México encabeza la lista de países del continente americano con el más alto índice de impunidad. El promedio nacional del Índice de Impunidad (IGI-MEX 2018), que tomó en cuenta a las 32 entidades, aumentó a 69.84 puntos en comparación con la última medición de 2016 que fue de 67.42 (Le Clercq Ortega, 2018, p. 7).

Otro índice relevante es la pobreza, lo cual significa que los ingresos están por debajo de la línea de bienestar, pues resultan insuficientes para comprar la canasta de alimentos, bienes y servicios básicos; según el Consejo Nacional de Evaluación de la Política de Desarrollo Social (CONEVAL), en el 2012 el porcentaje de pobreza era de $45.5 \%$, en el 2014 era $46.2 \%$ y en el 2016 era de $43.6 \%$ a nivel nacional, que equivale a $53,418,151$ personas y el porcentaje de pobreza extrema en 2012 era de $9.8 \%$, en 2014 era de $9.5 \%$ y en el 2016 era de

\section{(c) (i) (2)}

La Revista Estudios es editada por la Universidad de Costa Rica y se distribuye bajo una Licencia Creative Commons Atribución-NoComercial-CompartirIgual 3.0 Costa Rica. Para más información envíe un mensaje a 
$7.6 \%$, que equivale a $9,375,581$ personas en pobreza extrema a nivel nacional (Consejo Nacional de Evaluación de la Política de Desarrollo Social, 2018). En cuanto al analfabetismo, en 2010 6.9\% de la población no sabía leer ni escribir; en el 2015 el 5.5\% de la población era analfabeta (INEGI, 2015).

Los datos anteriores son necesarios para dar un panorama a grandes rasgos del país, puesto que, según la pirámide de Maslow, las conciencias de Barrett y las valencias corporales de Rico Bovio, para lograr individuos satisfechos se requiere tener primero cubiertas de una manera suficiente las necesidades físicas y de seguridad-supervivencia, situación previa que se nota que no se cumple en México.

Aún con este panorama poco favorecedor, la política cultural debe trabajar para dotar de capital cultural a los mexicanos. Véase qué sucede.

Existen múltiples definiciones de cultura, de las cuales se toman dos: una se refiere al punto de vista antropológico que trata de la identidad social; el otro se refiere a la cultura artística, a su producción y a sus productos. Ambas posturas coexisten, se sostienen juntas, se influyen entre sí. La industria cultural se desarrolla y trabaja en conjunto con las políticas culturales públicas que se traducen en programas, estímulos, gestiones, financiamientos, etc., que no se encuentran centralizadas en un solo organismo. Así como la cultura es multifacética y presenta múltiples aristas, también las políticas culturales se ven en la necesidad de relacionarse con otras áreas para garantizar su efectividad, a través de la relación necesaria entre disciplinas que convergen para comprender y manejar el abundante bagaje cultural de una localidad, región o Estado. De modo que se debe entender la cultura desde el entrecruzamiento de disciplinas cuyo fin es el desarrollo humano y donde es partícipe el Gobierno con sus políticas culturales.

\section{(C) $(00$}

La Revista Estudios es editada por la Universidad de Costa Rica y se distribuye bajo una Licencia Creative Commons Atribución-NoComercial-CompartirIgual 3.0 Costa Rica. Para más información envíe un mensaje a 


\section{Datos históricos relevantes de la política cultural mexicana}

En el presente sub-apartado se define la política cultural según Arturo Chavolla como:

Conjunto de todas aquellas acciones o intenciones por parte del Estado, la comunidad o instituciones civiles tendientes a orientar el desarrollo simbólico, satisfacer las necesidades culturales de una sociedad y obtener consenso para la transformación social o el establecimiento de un nuevo tipo de orden entre las personas. Además, ese esfuerzo debe poseer como meta la socialización de los productos y la democratización de sus resultados para que toda la población, independientemente de su credo religioso, su posición social, edad o postura política, tenga acceso al patrimonio generado por la sociedad en su conjunto (Chavolla, 2010).

Se toma la tesis anterior sólo se le agrega que las políticas culturales son las acciones gubernamentales (el hecho de ser gubernamentales no indica que siempre sean gratuitas; pueden tener un costo según se requiera o adapte a la necesidad). Otras son administradas por sociedades no lucrativas (se excluyen las industrias culturales de aquellas que solo tienen fines "nobles"), que buscan ensalzar y dar a conocer a todas las sociedades, propias y ajenas, el patrimonio tangible e intangible que se considera idóneo para representar o que representa a cierta población. Por lo mismo se expresan a través de varios medios de comunicación, donde se clasifican las obras dentro de la cultura del planeta, lo cual provoca efectos que a largo plazo modifican a las poblaciones y su forma de ser contemplados y auto-contemplarse. Las políticas culturales públicas no están deslindadas de las industrias culturales privadas y de otros procesos o entes culturales al momento de crear identidades, puesto que entre todas contribuyen a la formación del ciudadano y a la identidad social.

\section{(c) (i) (2)}

La Revista Estudios es editada por la Universidad de Costa Rica y se distribuye bajo una Licencia Creative Commons Atribución-NoComercial-CompartirIgual 3.0 Costa Rica. Para más información envíe un mensaje a 
A continuación se dará un esbozo histórico de las políticas culturales más importantes en México. Se presentarán también los estudios realizados por otros autores, que se consideran relevantes para esta investigación. Además se expondrá la influencia de los medios de comunicación y las tecnologías de la información en nuestra cultura.

En 1900, México presentaba un porcentaje de analfabetismo cercano al $78 \%$. Diez años después, la población analfabeta de 6 años o más que no sabía leer ni escribir era del 72\% (INEGI, 2008), que fue cuando se inauguró la Universidad Nacional Autónoma de México (UNAM) y empezó a surgir la revolución como nuevo paradigma, en el proceso de reconstrucción y redefinición de la identidad nacional. El ethos mexicano se fundió con el ideario revolucionario en una alianza que marcó el porvenir del siglo XX: había que romper con lo previo, marcar un punto de inflexión. Era un momento de modificaciones (Ortiz Espinoza, Gutiérrez Díaz, \& Hernández Alba, 2016). Uno de los puntos estructurales fue la fundación de la Secretaría de Educación Pública (SEP), a través del decreto en el Diario Oficial de la Federación del 3 de octubre de 1921, donde quedó como titular el Lic. José Vasconcelos Calderón. Su estructura interna era la siguiente: El Departamento Escolar, donde se integraron todos los niveles educativos; el Departamento de Bibliotecas, cuya búsqueda era garantizar materiales de lectura para la educación y el Departamento de Bellas Artes para coordinar las actividades artísticas complementarias de la educación. Con esta estructura y con lo que se conoció como "misiones culturales", en 1919 el número de maestros de educación primaria aumentó de 9 mil 560, donde en 1921 eran 25 mil 312; es decir aumento al $164.7 \%$ su capacidad (SEP, 2013). La política de Estado determinó desde el primer cuarto del siglo XX, que en México la actividad cultural de mayor presencia y trascendencia: museos, orquestas sinfónicas, y otras actividades culturales, dependerían del financiamiento y apoyo del Estado mexicano, serían un apoyo a la educación integral de los estudiantes. Así mismo se buscó moldear una identidad que representara a todos los mexicanos; este proyecto cultural

La Revista Estudios es editada por la Universidad de Costa Rica y se distribuye bajo una Licencia Creative Commons Atribución-NoComercial-Compartirlgual 3.0 Costa Rica. Para más información envíe un mensaje a 
también dependía de la Secretaría de Educación Pública. La función de la SEP era velar por la educación y la cultura en México. Con el paso de los años se vio la necesidad de crear órganos que solo se enfocaran a cuestiones culturales y es así como surgen el Instituto Nacional de Antropología e Historia (INAH) en 1939 y el Instituto Nacional de Bellas Artes (INBA) en 1946, ambas instituciones descentralizadas de la SEP (SC, 2016).

En las décadas siguientes se fundaron universidades públicas y privadas, así como institutos tecnológicos. En 1934 surgió el Fondo de Cultura Económica, una empresa editorial del Estado que fue dirigida por Daniel Cossío Villegas; en 1959 surgió la Comisión Nacional de Libros de Texto Gratuitos (CONALITEG). Como se aprecia, fueron años de fomentar un proyecto de cultura nacional. El Consejo Nacional para la Cultura y las Artes se creó en 1988, con el fin de coordinar las políticas culturales; su antecedente inmediato fue la Subsecretaría de Cultura de la Secretaría de Educación Pública, pero a través de un decreto de 1988 se desprendió de ésta y se le anexaron todas las instituciones, entidades y dependencias de otras secretarías con funciones de carácter cultural. Entre los motivos para su fundación se encuentra favorecer el estímulo y fomento de la creación tanto artística como cultural, busca garantizar la plena libertad de los creadores. Se indicó que debía alentar las expresiones de distintas regiones y grupos sociales del país, para así promover, preservar y enriquecer los bienes artísticos, culturales y el patrimonio histórico con que cuenta la Nación. En 1989 se estableció el Fondo Nacional para la Cultura y las Artes, un programa dedicado a la creación, promoción, difusión y producción cultural y artística (SC, 2016). CONACULTA estuvo en labores aproximadamente durante 28 años, hasta que por decreto presidencial en el 2015 , se decidió darle mayor relevancia a la Cultura y se creó la Secretaría de Cultura, que entró en función hasta el 2016. Con su creación, la política cultural del gobierno federal pasó de ser administrada como un subsector de la Secretaría de Educación Pública, a ser ejecutada de manera autónoma por una Secretaría de Estado (Villaseñor Anaya, 2016, p. 8). A través

La Revista Estudios es editada por la Universidad de Costa Rica y se distribuye bajo una Licencia Creative Commons Atribución-NoComercial-CompartirIgual 3.0 Costa Rica. Para más información envíe un mensaje a 
del artículo 41 de la Ley Orgánica de la Administración Pública Federal se le otorgaron sus funciones a la Secretaría de Cultura, prácticamente las mismas con que contaba antes el CONACULTA.

En el Plan Nacional de Desarrollo del 2013 al 2018 (PND 2013-2018), se estableció que la meta nacional "México con Educación de Calidad", tiene entre sus objetivos ampliar el acceso a la cultura como un medio para la formación integral de los ciudadanos; por lo cual resulta necesario implementar una política de Estado capaz de situar a la cultura entre los servicios básicos brindados a la población, así como proveer la infraestructura adecuada, preservar el patrimonio cultural del país, vincular la inversión del sector con otras actividades productivas e impulsar una agenda digital en la materia (Villaseñor Anaya, 2016, p. 11).

Como la Secretaría de Cultura (y ex-CONACULTA) no propuso un concepto general de cultura, se acude a la lectura de su misión y visión:

Misión: La Secretaría de Cultura es la institución encargada de preservar de forma integral el patrimonio cultural de la Nación en sus diversas manifestaciones artísticas y culturales así como estimular los programas orientados a la creación, desarrollo y esparcimiento de las mismas. Las acciones están encaminadas a mantener un compromiso profesional que beneficie a toda la sociedad mexicana con la promoción y difusión de todo el sector cultural y artístico.

Visión: Convertirse en la institución de mayor relevancia nacional en los sectores cultural y artístico. Estimulará la creación artística y cultural con la garantía de que los creadores tengan plena libertad, esto en reconocimiento de que el Estado debe promover y difundir el patrimonio y la identidad nacional. Elevará la presencia del arte y la cultura nacional a través de proyectos, exposiciones, eventos culturales y cinematografía...(SC, 2016).

Se encuentra en la misión y visión de la Secretaría de Cultura la afirmación de la pluralidad artística y cultural; así mismo se habla de ética al buscar el beneficio de toda la sociedad mexicana. Menciona el respeto a la libertad de los creadores, da indicios nacionalistas y alienta a la protección de la identidad 
nacional y su patrimonio a través de la promoción y difusión que permitan elevar la presencia del arte y la cultura con diversas propuestas. Aunque la cultura en sentido antropológico y la artística no parten del mismo concepto de "cultura", la SC trabaja con ambas, busca promover y difundir los trabajos de los artistas y proteger el patrimonio histórico y monumental a través de varios programas.

En cuanto a la distribución del Producto Interno Bruto (PIB) en el sector cultural, representó el 3.3\% del PIB en el 2016; se calcula que aportó 617,397 millones de pesos. Según datos de la Cuenta Satélite de la Cultura de México, en el 2015 contó con el 3.4 \% del PIB y aportó 596,918 millones de pesos. Hubo un declive del .1\% del 2015 al 2016; se encuentra una mayor cantidad de dinero debido a que el PIB en México creció, sin embargo la inversión en prácticas culturales decreció. En años anteriores (2008 al 2014), el PIB cultural parecía atascado, pues fluctuó entre $2.7 \%$ y el 2.8\%; ahora "sube" véase tabla 1 y figura 5. 
Distribución porcentual del PIB del sector de la cultura por áreas generales (\%)

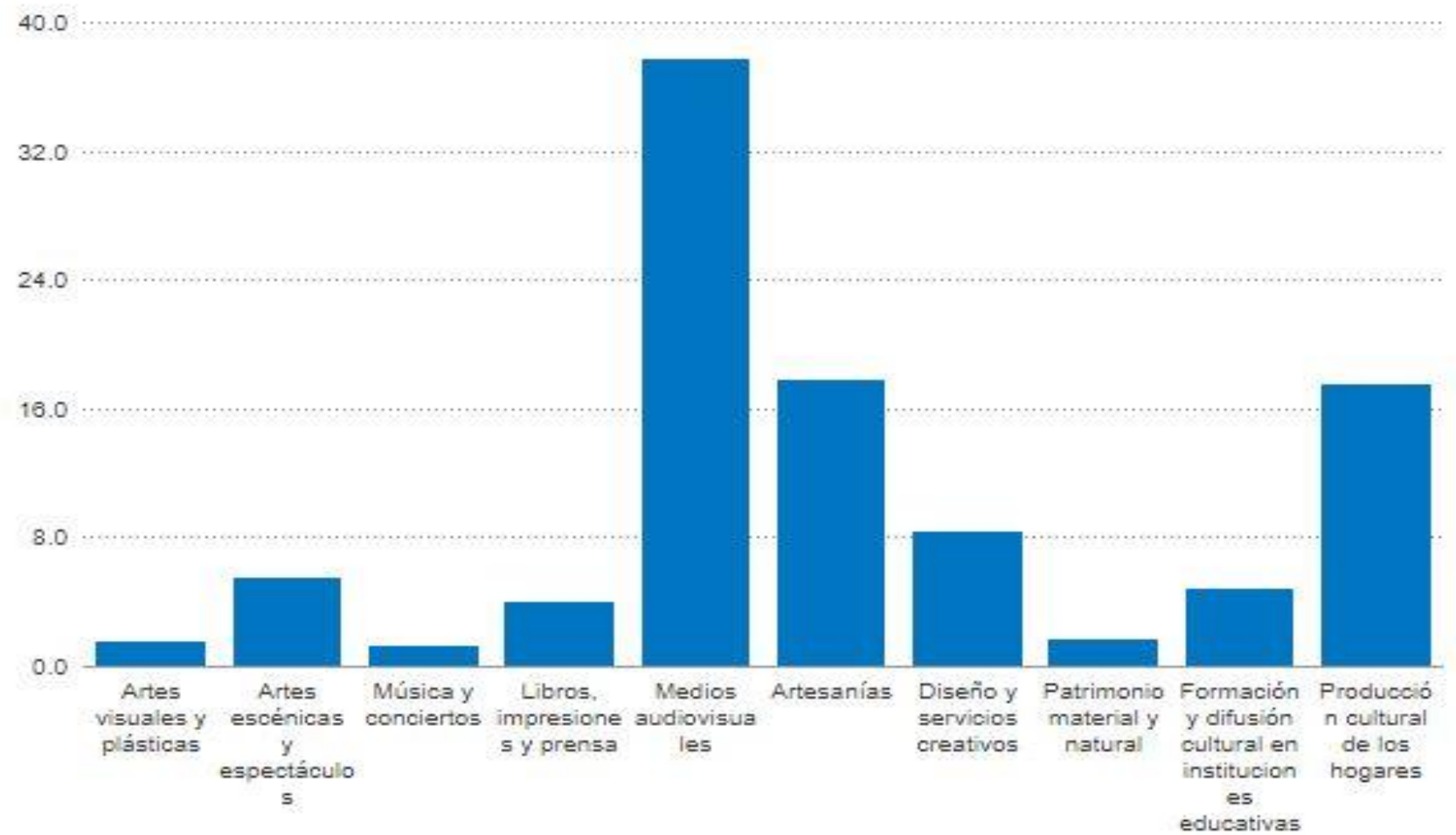

Figura 5.- En esta figura se observa la distribución porcentual del PIB del sector de la cultura por áreas generales en \% que se obtuvo en el INEGI en enero del 2018 (INEGI, 2018), y se encuentran los siguientes datos 37.7\% en Medios Visuales, 17.8\% en Artesanías y le sigue con 17.5\% la Producción cultural de los hogares, $8.3 \%$ en los Diseños y servicios Creativos, con 5.5\% Artes escénicas y Espectáculo, 4.8\% en Formación y difusión cultural en Instituciones educativas; $3.9 \%$ en Libros, impresiones y prensa, $1.7 \%$ en Patrimonio material y natural y 1.5\% en Artes visuales y plásticas entre otras.

\section{@ $\odot \Theta \odot$}

La Revista Estudios es editada por la Universidad de Costa Rica y se distribuye bajo una Licencia Creative Commons Atribución-NoComercialCompartirIgual 3.0 Costa Rica. Para más información envíe un mensaje a revistaestudios.eeg@ ucr.ac.cr. 
Tabla 1

PIB anual en la cultura "Basado en: (INEGI, 2013, 2014a, 2014b, 2017, 2018)"

\begin{tabular}{lllllllllll}
\hline & 2008 & 2009 & 2010 & 2011 & 2012 & 2013 & 2014 & 2015 & 2016 & 2017 \\
\hline PIB & 2.7 & 2.8 & 2.7 & 2.7 & 2.7 & 2.8 & 2.8 & 3.4 & 3.3 & \\
\hline
\end{tabular}

Se completó con datos de diversos informes de cuentas satélites de cultura y de la página de INEGI, para representar el PIB cultural a través de los años. El producto interno bruto en el sector de la cultura del 2008 al 2014 se calcula con el cambio de año base del 2008; el 2015 y 2016 se calculan con el cambio de año base del 201; se hace la aclaración de que el 2015 con el año base del 2008 muestra el PIB de 2.9 y con el año base del 2013 presenta un porcentaje de 3.4 .

Tabla 2

Antecedentes de estudios de consumo cultural "basado en:(INEGI, 2012, 2014c; Piedras et al., 2011; SC, 2010, 2018)"

\begin{tabular}{lc}
\hline Nombre del estudio & Año \\
\hline Encuesta Nacional de Hábitos, Prácticas y Consumo Culturales & 2010 \\
Índice de Capacidades y Aprovechamiento Cultural de los Estados & 2011 \\
(ICACE) & 2012 \\
Encuesta Nacional de Consumo Cultural de México & 2002, \\
Encuesta Nacional sobre Uso del Tiempo (ENUT) & 2009 y \\
& 2014. \\
Sistema de Información Cultural (SIC) & N/A \\
\hline
\end{tabular}

Elaboración propia con fuentes consultadas en la presente tabla.

La tabla superior es de relevancia, ya que se presentan los estudios recientes de consumo cultural y a través de ellos se puede vislumbrar la realidad del consumo cultural, sea público o privado; el ICACE permite medir cómo se encuentran los recursos, producción y apropiación de elementos culturales, mide lo que se tiene y que se ha hecho con ello en cada estado de la República Mexicana. La encuesta nacional de hábitos, prácticas y consumo culturales del 2010, es la que usan los gobiernos actuales para justificar sus programas $u$ ofertas.

México cuenta con el Sistema de Información Cultural (SIC), el cual es la plataforma de la SC que conjunta y ofrece información sobre el patrimonio y los recursos naturales del país que están al servicio de la población; esta página se actualiza a través de la Red Nacional de Información Cultural (RENIC para efectos gubernamentales o RNIC para efectos del presente trabajo). A través de RNIC los

La Revista Estudios es editada por la Universidad de Costa Rica y se distribuye bajo una Licencia Creative Commons Atribución-NoComercial-CompartirIgual 3.0 Costa Rica. Para más información envíe un mensaje a 
institutos, consejos, secretarías de cultura de las 32 entidades del país, participan de manera activa para mejorar, construir y actualizar la información en la SIC. En las Figuras 6 y 7 se enumeran el total de cada ámbito abarcado a nivel nacional por la SC.

\section{(c) (i) (2)}

La Revista Estudios es editada por la Universidad de Costa Rica y se distribuye bajo una Licencia Creative Commons Atribución-NoComercial-CompartirIgual 3.0 Costa Rica. Para más información envíe un mensaje a revistaestudios.eeg@ucr.ac.cr. 


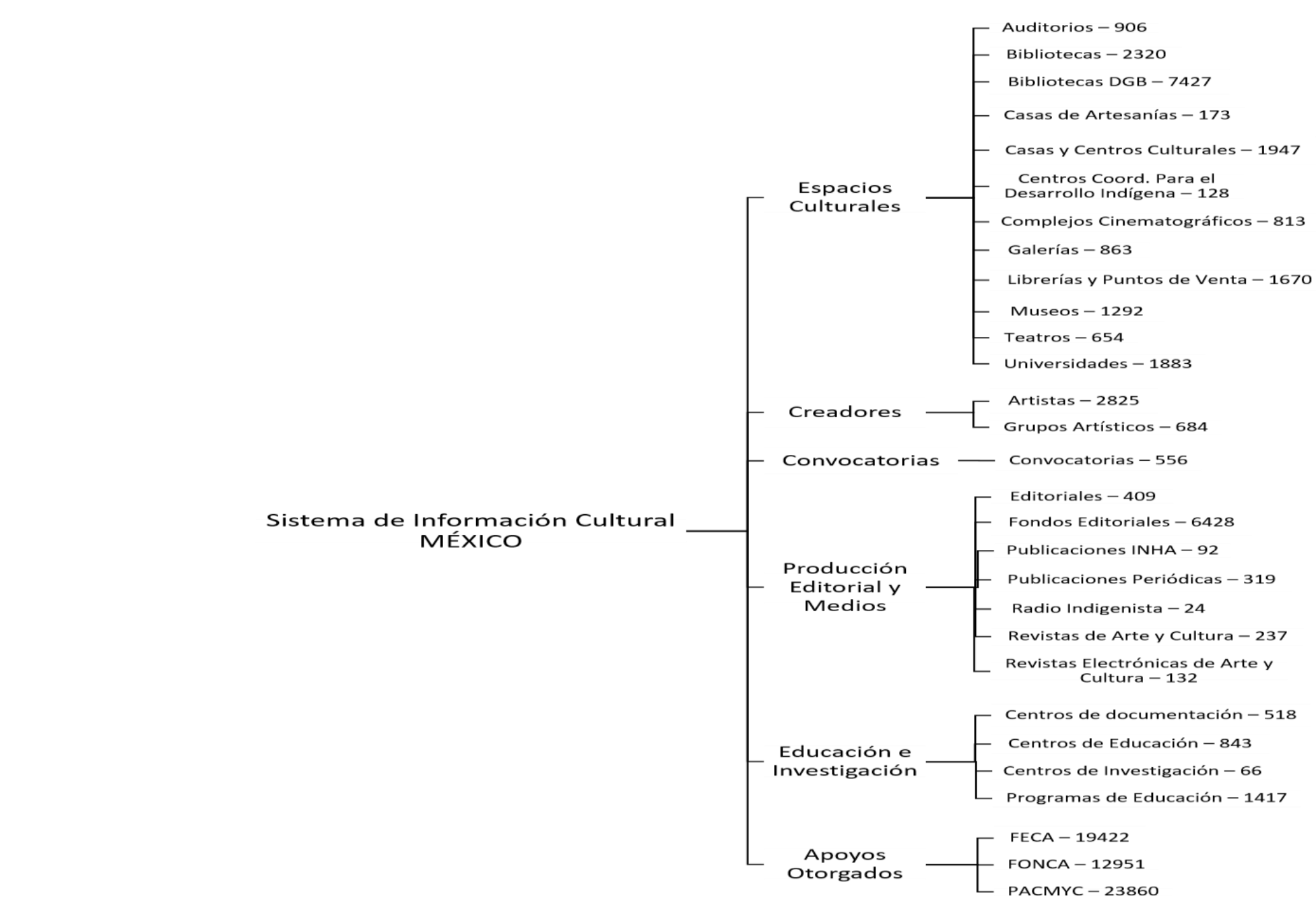

Rico Bovio Arturo

Figura 6.- En esta figura se observa la oferta de infraestructura cultural federal, basada en el SIC de enero del 2018. Es la sumatoria hasta la fecha (SC, 2018).

\section{@ $\odot \Theta \odot$}

La Revista Estudios es editada por la Universidad de Costa Rica y se distribuye bajo una Licencia Creative Commons Atribución-NoComercialCompartirIgual 3.0 Costa Rica. Para más información envíe un mensaje a revistaestudios.eeg@ ucr.ac.cr. 


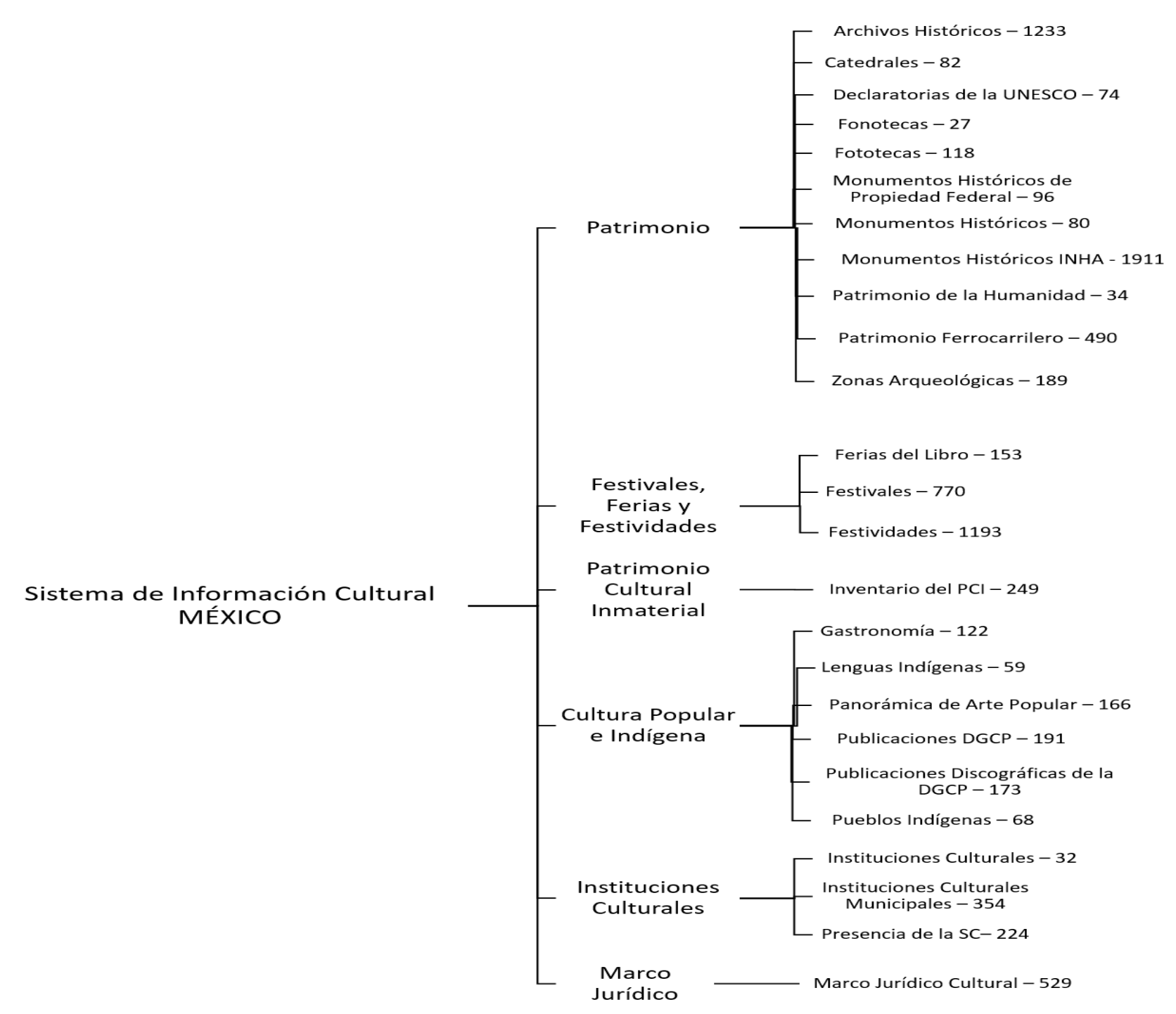

Rico Bovio Arturo

Figura 7.- (Continuación) La oferta en la infraestructura cultural federal, basada en el SIC de enero del 2018. Es la sumatoria hasta la fecha (SC, 2018).

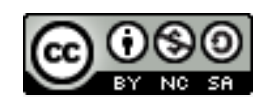

La Revista Estudios es editada por la Universidad de Costa Rica y se distribuye bajo una Licencia Creative Commons Atribución-NoComercialCompartirIgual 3.0 Costa Rica. Para más información envíe un mensaje a revistaestudios.eeg@ucr.ac.cr. 


\section{Interconexiones culturales}

El gobierno de México se encuentra estructurado en Secretarías o departamentos piramidales, espacios institucionales donde se gestionan, entre otros, programas cuyo fin es promover la creación artística para que llegue a públicos determinados y en última instancia a cada ser humano. El principal promotor de la cultura pública en México es la Secretaria de Cultura; sin embargo, otras secretarías también son esenciales, porque sin ellas el trabajo de la SC seria incompleto y no cumpliría sus objetivos. Las secretarías con las que se observa una relación más estrecha son la Secretaría de Economía, la Secretaría de la Educación Pública, la Secretaría de Turismo, la Secretaria de Medio Ambiente y Recursos Naturales, la Secretaría de Gobernación, la Secretaría de Relaciones Exteriores. La Secretaría de Economía busca fomentar la productividad y competitividad de la economía mexicana, fortalece el mercado interno atrayendo inversión extranjera que mejore las condiciones de vida de los mexicanos, promueve la formación de emprendedores, que ocuparían el primer nivel dentro del ámbito empresarial. Si se tienen artistas, gestores culturales y promotores que emprendan pequeñas y medianas empresas relacionadas con el fomento a la cultura, de manera indirecta se benefician de la política cultural y promueven la creación de públicos, de igual manera generan empleos. De esta Secretaría depende el comercio exterior que se encarga de regular las exportaciones e importaciones; la cultura pasa por una serie de normatividades para poder cruzar fronteras y pagar aranceles e impuestos según la Ley de Impuestos Generales de Importación y de Exportación (SE, 2018). Por otro lado la educación y la cultura se encuentran paralelas, ya que ocupan un lugar esencial en el desarrollo social. En el caso de México la Cultura siempre ocupó un papel secundario, dependiente de la Secretaría de Educación Pública (SEP). Actualmente son dos secretarias distintas, donde la de educación se encarga de la educación científica y deportiva 
en todos los niveles, de sus contenidos, programas de estudio y calendarios. En base a eso de manera general el conocimiento cultural que tenga un individuo se deberá, en buena medida, al aporte que hace la educación formal; así mismo la SEP protege los derechos de autor y patentes (SEP, 2018).

De gran importancia para las políticas culturales, la Secretaría de Turismo (ST) aporta a la cultura de diversas formas. Un ejemplo contundente de ello es el programa "Pueblos Mágicos" (Secretaría de Turismo, s/f), que en colaboración con otras instancias busca reconocer la riqueza cultural e histórica que encierran ciertas localidades, que buscan crear y promover localización. A través de la atracción de viajeros nacionales e internacionales, lo cual permite el flujo monetario de divisa nacional e internacional (ST, 2018).

Aunque pareciera no tener ninguna relación, la Secretaría del Medio Ambiente y Recursos Naturales asegura la óptima protección, aprovechamiento y conservación de los recursos naturales del país, lo cual modera el patrimonio cultural ecológico de la nación, implementa los programas que buscan la sustentabilidad de zonas turísticas y el manejo adecuado de residuos contaminantes (SMARN, 2018). A diferencia de la anterior, la Secretaría de Gobernación busca fomentar la convivencia armónica, la paz social y el bienestar de los ciudadanos, a través de combatir la ilegalidad y regular la economía informal del país, lo cual beneficia a la cultura; también se encarga de toda la gestión relacionada con el Archivo General de la Nación (AGN): la reproducción, exportación, venta y protección de su acervo histórico. La historia representa parte de la identidad de un pueblo y permite reafirmar su cultura (SG, 2018). Finalmente la Secretaría de Hacienda y Crédito Público se encarga de la evaluación presupuestaria de la administración pública federal, con el fin de hacer un reparto de los bienes económicos recaudados a través de la Tesorería de la Federación (TESOFE) y llevar un registro de egresos e ingresos. Además la SHCP realiza una vasta tarea de promoción y difusión de la riqueza patrimonial que tiene en custodia y que está conformada por sus recintos históricos, acervos hemerográficos y 
bibliográficos, por ejemplo los palacios (el Palacio Nacional es el más importante a nivel federal) (SHCP, 2018).

De esta breve relación se observa que dentro de las políticas culturales y con el fin de promover la cultura y su desarrollo, las secretarías anteriores y otras no mencionadas participan de manera conjunta para alcanzar el objetivo cultural; la combinación de los recursos de dos o más secretarías ofrece la posibilidad de resolver un problema, aunque esos recursos aparentemente pertenecen a disciplinas diferentes.

Se encuentra que es necesario realizar un análisis más a fondo de estas relaciones intersecretariales y fomentar el trabajo conjunto entre cultura, educación, economía, ecología, contabilidad, administración, comercio exterior, entre otros; para lograr las metas, no solo del PND 2013-2018, sino a nivel nacional e internacional, que persigue el objetivo común de la formación integral de los ciudadanos, mediante el implemento de distintas convocatorias, programas, concursos y acciones que cooperan entre sí para obtener un desarrollo pleno humano-cultural de todos los sectores sociales.

Cuando se ubica en el nivel internacional se encontró que, además de combinarse entre sí las políticas públicas internas del país y sus estados, existen organismos internacionales que actúan con independencia de las secretarías de cualquier país; realizan un trabajo conjunto con los organismos nacionales, mediante convenios que buscan estimular la cultura como identidad y desarrollo social de los diversos países.

\section{Análisis crítico del panorama cultural}

Se ha mostrado las conexiones que existen entre diversas secretarías, sus políticas culturales federales y estatales, sus enunciados y lo que debería ser desde la perspectiva de las instituciones internacionales. Es el caso de la Secretaría de Cultura en México, que busca asumir los lineamientos del orden 
internacional. Conforme al Derecho Internacional el Estado mexicano tiene el deber de promocionar y proteger la cultura, sin monopolizarla. En la óptica de México se escapa que la cultura no solo son las Bellas Artes, sino la educación, la moda, la cocina, el medio ambiente, la ciencia, las religiones y las culturas populares; sólo estas dos últimas expresiones de la identidad nacional se contemplan en algunos actos cívicos y sociales.

Retomando el tema de la relación entre las dependencias nacionales mexicanas y las internacionales, se halla el problema del desdibujamiento de las metas culturales. Las instituciones públicas no tienen por costumbre la colaboración entre ellas, la eficaz rendición de cuentas, ni la transparencia, lo que provoca que la reglamentación en materia de políticas, programas, leyes y proyectos culturales no se concrete hasta sus últimos términos; el alcance a los públicos a donde se ha destinado es insuficiente en sus resultados, gracias a la impunidad, la corrupción, los celos entre funcionarios, entre otros factores. Esto es común en países subdesarrollados como en el caso de México.

A reserva de profundizar en otro ensayo sobre esta materia, se afirma de manera general que no hay suficiente personal capacitado en el ámbito de la cultura para atender las necesidades de los artistas y de los públicos. Además, se experimenta a menudo que quienes asignan el presupuesto de cultura ejercen el poder arbitrariamente, usan ventajosamente su posición jerárquica. Los mandos y los operadores de los programas culturales, con honrosas excepciones, cumplen con su trabajo pero no se esfuerzan, ni les importa; ejercen su trabajo dentro del margen de sus obligaciones mínimas dentro de la institución, excepto cuando se trata de certificaciones o de supervisión por otros departamentos de gobierno o de la iniciativa privada y del sector social.

Al hacer una revisión de la página del SIC para esbozar una gráfica de resultados, se encontró que desde el 2012 no permite las búsquedas por 
anualidades; al poner un año específico siempre arroja todos los beneficiarios que existen en la página del SIC sin importar el año. Se hizo revisión de los apoyos otorgados en Chihuahua por el FONCA, se encontró que los últimos datos actualizados son del 2008; así mismo aparece hasta 3 veces en un mismo año un beneficiario o beneficiaria, con el mismo concepto de apoyo y la misma fecha de emisión, por lo que se concluye que o todos los apoyos se otorgan a un mismo creador/artista o hay datos aumentados en las cifras que otorga el SIC; por lo cual sus datos son atrasados, irreales o desvinculados a la realidad,

De esta búsqueda de información se deduce que además de la desigualdad económica y educativa y los diversos tipos de violencia en el contexto social más desfavorecido de bienes y servicios, existe una diversidad cultural compleja, no hay una forma única de ser del mexicano. A falta de estudios abocados a detectar las carencias y las problemáticas culturales específicas de los distintos sectores sociales, en ausencia de diagnósticos se diseñan las políticas y estrategias desde las instituciones culturales centrales, ubicadas en la ciudad de México y en las capitales de los estados, sin tomar en cuenta, entre otros factores, a los actores y beneficiarios de la cultura, así como la deficiente vinculación entre todas las áreas de gobierno que tienen algo o mucho que ver con la cultura, tales como: educación pública, turismo, economía, industrias particulares, relaciones exteriores, entre otras.

Urge vincular las prácticas culturales de la ciudadanía y sus necesidades con el marco legal e institucional que procura tutelarlas, para que no se queden a merced de un discurso político demagógico desvinculado de la realidad y de los tratados internacionales que se reconocen formalmente a nivel federal, aunque sus estrategias y prácticas operativas son inconsistentes. Como existe una amplia manipulación de las cifras de los resultados en las estadísticas oficiales, queda un largo camino por recorrer para proteger a la cultura nacional, al patrimonio cultural edificado, a las

\section{(c) (i)(2)}

La Revista Estudios es editada por la Universidad de Costa Rica y se distribuye bajo una Licencia Creative Commons Atribución-NoComercial-CompartirIgual 3.0 Costa Rica. Para más información envíe un mensaje a 
lenguas, tradiciones y costumbres de las etnias originarias, a los artistas, artesanos y consumidores, con un buen marco jurídico que realmente se aplique. En teoría están puestas las bases institucionales, pero si no hay desarrollo humano ¿qué pasa? Para dar respuesta a estas y a otras cuestiones relacionadas con la Cultura, se requiere de un estudio interdisciplinario complejo, que permita a ciudadanos y gobernantes encontrar la mejor manera de reforzar las políticas públicas culturales, para ofrecer mejores resultados a la sociedad en general.

\section{Bibliografía}

Barrett, R. (2018). Barret values centre. Recuperado a partir de https://www.valuescentre.com/mapping-values/barrett-model/personalconsciousness

Chavolla, A. (2010). Política Cultural. Recuperado a partir de http://www.cecies.org/articulo.asp?id=193

Consejo Nacional de Evaluación de la Política de Desarrollo Social. (2018). medición de la pobreza. Recuperado a partir de https://www.coneval.org.mx/Medicion/MP/Paginas/Pobreza_2016.aspx

INEGI. (2008). Porcentaje de Población Analfabeta obtenido de Panorama Educativo de México. Recuperado a partir de http://www.inee.edu.mx/bie/mapa_indica/2010/PanoramaEducativoDeMexico/ CS/CS03/2010_CS03_c-vinculo.pdf

INEGI. (2012). Encuesta Nacional de Consumo Cultural de México (ENCCUM). Recuperado a partir de http://internet.contenidos.inegi.org.mx/contenidos/Productos/prod_serv/conteni dos/espanol/bvinegi/productos/encuestas/hogares/encc/2012/ENCCUM2012. pdf

INEGI. (2013). Cuenta Satélite de la Cultura de México, 9. Recuperado a partir de

La Revista Estudios es editada por la Universidad de Costa Rica y se distribuye bajo una Licencia Creative Commons Atribución-NoComercial-Compartirlgual 3.0 Costa Rica. Para más información envíe un mensaje a 
https://www.gob.mx/cultura/documentos/cuenta-satelite-de-la-cultura-demexico

INEGI. (2014a). Cuenta Satélite de Cultura 2008-2011, (71), 11. Recuperado a partir de https://www.gob.mx/cultura/documentos/cuenta-satelite-de-la-culturade-mexico

INEGI. (2014b). Cuenta satélite de la cultura de méxico, 2014, 12.

INEGI. (2014c). Encuesta Nacional sobre Uso del Tiempo 2014. Recuperado a partir

de

http://www.beta.inegi.org.mx/proyectos/enchogares/especiales/enut/2014/

INEGI. (2015). encuesta intercensal 2015. Recuperado a partir de http://www.beta.inegi.org.mx/proyectos/enchogares/especiales/intercensal/def ault.html?init=1

INEGI. (2017). Cuenta satélite de la cultura de méxico, 2015. Recuperado a partir de

http://www.inegi.org.mx/saladeprensa/boletines/2017/cscm/cscm2017_06.pdf

INEGI. (2018). PIB cultura. Recuperado a partir de http://www.inegi.org.mx/est/contenidos/proyectos/cn/Cultura/default.aspx

Le Clercq Ortega, J. A. (2018). índice global de impunidad igi - mex 20181. Recuperado a partir de http://www.udlap.mx/igimex/assets/files/2018/igimex2018_ESP.pdf

Maslow, A. H. (1943). A Theory of Human Motivation. Recuperado a partir de http://psychclassics.yorku.ca/Maslow/motivation.htm

Ortiz Espinoza, Á., Gutiérrez Díaz, M., \& Hernández Alba, L. A. (2016). Identidad, cohesión y patrimonio: Evolución de las políticas culturales en México. Revista Humanidades: Revista de la Escuela de Estudios Generales, 6, 1-39. Recuperado a partir de https://dialnet.unirioja.es/servlet/articulo?codigo $=5523893$

Piedras, E., Rojón, G., Gamboa, D., Arriaga, A., Rivera, A., Ramírez Fraga, E., \& Gutierrez, H. (2011). Índice de Capacidades y Aprovechamiento Cultural. 
Recuperado

a

partir

Rico Bovio Arturo

http://www.nomismae.net/nomismae_ok/pdf/Nomismae-ICACE_2011.pdf

PNUD. (1990). Desarrollo Humano Informe 1990. https://doi.org/958-601-283-2

Rico Bovio, A. (1990). Las fronteras del cuerpo. Crítica de la corporeidad. (S. A. de C. V. Editorial Joaquín Mortiz, Ed.) (1ra ed.). México.

Rico Bovio, A. (2017). Muerte y resurreción del cuerpo. (Plaza Valdez S.A. de C.V. \& Universidad Autónoma de Chihuahua, Eds.) (1ra ed.). México.

SC. (2010). Encuesta Nacional de Hábitos, Prácticas y Consumo culturales. Recuperado a partir

de http://www.cultura.gob.mx/encuesta_nacional/\#.WP14Q9I1_IV

SC. (2016). Acerca de Conaculta. Recuperado a partir de http://www.cultura.gob.mx/acerca_de/

SC. (2018). Sistema de Información Cultural. Recuperado a partir de http://sic.cultura.gob.mx/index.php

SE. (2018). SE. Recuperado a partir de https://www.gob.mx/se/archivo/acciones_y_programas

Secretaría de Turismo. (s/f). Pueblos mágicos de México. Recuperado a partir de http://www.pueblosmexico.com.mx

Secretariat Transparency International, \& International, T. (2016). Índice de Percepción de la Corrupción de Transparency International, 100. Recuperado a partir de https://transparencia.org.es/wpcontent/uploads/2017/01/tabla_sintetica_ipc-2016.pdf

SEP. (2013). Creación de la Secretaría de Educación Pública. Recuperado a partir de https://www.gob.mx/presidencia/articulos/creacion-de-la-secretaria-deeducacion-publica

SEP. (2018). SEP. Recuperado a partir de https://www.gob.mx/sep

SG. (2018). SG. Recuperado a partir de https://www.gob.mx/segob

SHCP. (2018). SHCP. Recuperado a partir de https://www.gob.mx/hacienda

SMARN. (2018). SMARN. Recuperado a partir de https://www.gob.mx/semarnat

\section{c) (i) (2)}

La Revista Estudios es editada por la Universidad de Costa Rica y se distribuye bajo una Licencia Creative Commons Atribución-NoComercial-Compartirlgual 3.0 Costa Rica. Para más información envíe un mensaje a revistaestudios.eeg@ucr.ac.cr. 
ISSN 1659-3316

ST. (2018). ST. Recuperado a partir de https://www.gob.mx/sectur/

Rico Bovio Arturo

Transparency International. (2017a). evolución del índice de percepción de la corrupción (2009-2017). Recuperado a partir de https://transparencia.org.es/wp-content/uploads/2018/02/comparacion_ipc2009-2017.pdf

Transparency International. (2017b). Índice de Percepción de la Corrupción de Transparency International 2014, 100, 1-15. Recuperado a partir de https://transparencia.org.es/wp-content/uploads/2018/02/tabla_sintetica_ipc2017.pdf

Trejo Hermida, O. (2017). La necesidad de legislar en materia de salud mental positiva , como factor generador de Seguridad Nacional en México. Instituto de investigaciones estrategicas de la armada de México, 1-21. Recuperado a partir de http://www.cesnav.edu.mx/ININVESTAM/docs/docs_analisis/da_6617.pdf

Villaseñor Anaya, C. J. (2016). Cambios recientes en la institucionalidad de México, un proyecto en redefinición. Periférica: Revista para el análisis de la cultura $y$ el territorio, 17, 259-272. Recuperado a partir de http://revistas.uca.es/index.php/periferica/article/view/3281

\section{(C) $(00$}

La Revista Estudios es editada por la Universidad de Costa Rica y se distribuye bajo una Licencia Creative Commons Atribución-NoComercial-CompartirIgual 3.0 Costa Rica. Para más información envíe un mensaje a 